\title{
Analysing trends in caesarean sections at a tertiary care teaching hospital in South India: findings from a clinical audit using Robson criteria
}

\author{
Aruna Kumari Yerra, Mohammed Ismail Khan*
}

Department of Obstetrics and Gynecology, ESIC Medical College, Sanathnagar, Hyderabad, Telangana, India

Received: 16 January 2020

Revised: 17 February 2020

Accepted: 26 February 2020

*Correspondence:

Dr. Mohammed Ismail Khan,

E-mail: drismailobg@gmail.com

Copyright: (C) the author(s), publisher and licensee Medip Academy. This is an open-access article distributed under the terms of the Creative Commons Attribution Non-Commercial License, which permits unrestricted non-commercial use, distribution, and reproduction in any medium, provided the original work is properly cited.

\begin{abstract}
Background: Caesarean section (CS) is a potentially life-saving surgery when performed for indicated reasons. The rates of CS deliveries have sky rocketed in the last few years. A CS does not come without complications and risk and therefore its trends in all institutes should be audited for ensuring optimization of obstetric care standards.

Methods: The study was conducted as a retrospective analysis of all the CS deliveries for 12 months and their categorization using the WHO recommended Robson ten group classification system; with an aim to evaluate and understand the indication for each CS performed in the institute. The Robson was further subclassified to closely understand the circumstances in which the CS was performed in each group.

Results: In this study evaluated a total of 2831 deliveries out of which 1557 (55\%) were CS births. Out of these CS births, $48.5 \%$ were indicated for emergency indications. Class 5, 1 and 10 were the main contributors to the CS rate with $50.6 \%, 19.3 \%$ and $10 \%$ contributions respectively. From a total of 799 patients with previous CS, only $12.1 \%$ could have a successful trial of scar. The most common indications documented for Group 1 was foetal distress, cephalo pelvic disproportion and prolonged labour, in decreasing order. Among the singleton pre-terms who had a CS, a majority $(92.3 \%)$ were operated before the onset of labour.

Conclusions: The audit helped to understand the trends of CS in the institute and helped in the realizing that all the $\mathrm{CS}$ in the institute has questionable indications. This led to implementation of clinical and administrative reforms to ensure a reduction in unnecessary CS being performed.
\end{abstract}

Keywords: Audit, Caesarean section, Robsons criteria

\section{INTRODUCTION}

When indicated, caesarean section (CS) is one of the most indispensable part of obstetrics that has saved the lives of countless mothers and babies. It would not be an exaggeration to say that there is no other surgical procedure in obstetrics that can be used with the kind of expected prediction and confidence as offered by a CS, to improve maternal and foetal outcomes in indicated circumstances. Nevertheless, when the same CS is performed for un-indicated and unjustified reasons there is a paradigm shift in its nature from being a life-saving procedure to a life-threatening procedure. When such a CS is performed the mother and the child are placed at an unreasonable risk of morbidity and mortality. ${ }^{1,2}$ Moreover it also burdens the healthcare system by increasing expenditure of public resources and avoidable bed occupancy apart from deteriorating the quality of life of women in terms of post-operative morbidity and a reduction in their reproductive potential. 
The department of reproductive health and research, World Health Organisation (WHO) established, by the way of systematic reviews, in 2014 that CS rates in population more than $10 \%$ up to $30 \%$ have no additional benefits in terms of maternal and neonatal survival. ${ }^{5}$ However, the WHO acknowledges the fact that this cannot be applied to hospitals because different hospitals serve different populations and moreover based on the level of care provided by a particular hospital, the presenting characteristics of the patients and pregnancy outcomes vary considerably.

Several international bodies including the Royal College of obstetricians and gynaecologists recognize the fact that $\mathrm{CS}$ rates are increasing globally, but at the same time profess strongly that a CS should always be offered when medically indicated in maternal or foetal interest. ${ }^{6}$ Analyses of the four phases of National Family Health Survey, from 1992 to 2016 in India, reveal an increase in the National CS rate from around $2.9 \%$ in 1992 to $17.2 \%$ in $2016{ }^{7}$

An audit is a defined as a quality improvement process that aims to compare the existing quality of care and the outcomes thereof to explicitly defined standards and expected outcomes for the purpose of bringing a positive change in patient interest. ${ }^{8}$ In the wake of the present trends in CS, it is pertinent that CS rates be audited at local, regional and national levels to recognise issues if any and to formulate policies that reduce skewness in these rates if they are in patient care interest. Out of the several CS audits tools available, the Robson ten group classification system is the most widely used and accepted system. The WHO recommend the use of Robson Classification and also gives clear instructions on the implementation of this criteria for audit and record keeping. ${ }^{9}$ It is also mandatory that for setting a standard there needs to be uniformity in the assessment criteria.

This study is a part of the closed loop audit conducted to recognize the cause of high CS rate at our institution. The secondary outcomes of the study included a sub classification of each of the Robson class to more clearly understand the circumstances and reasons for taking up of each patient for a CS.

\section{METHODS}

The study is a result of the findings of a closed loop clinical audit, conducted for evaluating the high CS rates prevailing at ESIC Medical College, Hyderabad, which is a tertiary care teaching hospital, well equipped with operation theatres, neonatal intensive care unit, blood bank and a state of art labour room. The college has two trained obstetricians every night, on duty apart from a staff of 25 obstetricians who work full time. The pediatrics department has a trained pediatrician dedicated for neonatology services round the clock. The operation theatres are also covered round the clock by trained anesthetists. The audit was conducted after the ethical approval, and it retrospectively analyzed all the deliveries that occurred over one year from March 2017 to February 2018.

The case sheets of all the mothers admitted to the department of obstetrics and gynaecology for delivery during this period were retrieved from the medical records department. The doctor's notes were studied in detail in the case sheets of all the patients who underwent a CS. A clinical audit data extraction sheet was designed and filled carefully after making a detailed analysis of each case.

The clinical decisions made by the faculty were taken into consideration and given precedence over the findings and decisions taken by residents. Information regarding demographic details, socioeconomic status and immediate circumstances leading to delivery were collected and each delivery, whether vaginal or caesarean was then attributed to a Robson class based on guidelines in the World Health Organization implementation manual 2017. ${ }^{9}$ All the women who delivered were categorized into one of the ten Robson classes. As Robson is a mutually exclusive and completely inclusive classification no delivery could be placed in more than one group.

\section{Statistical analysis}

The data was then analyzed to evaluate the mode of delivery for women in each Robson's class. Later the contribution of caesarean delivery to each class and to the institutional CS rate was calculated.

\section{RESULTS}

The study recorded a total of 2831 deliveries during the study period, whose records were complete in all aspects. 1557 pregnant women were delivered by a CS which brings the $\mathrm{CS}$ rate to $55 \%$ compared to 1274 normal deliveries (45\%). Of the 1557 women who underwent a CS, 755 (48.5\%) were elective CS with premeditated decision, on the other hand, $802(51.5 \%)$ were emergency CS conducted when the maternal or foetal life was in imminent danger. Among the women who had vaginal births, $11.6 \%$ were induced and $88.4 \%$ were spontaneous in origin. The socio demographic and obstetric characteristics of these women are as described in Table 1.

Table 2 elucidates the categorization of women into the 10 Robson classes and their mode of delivery. Each class is further sub-classified as A, B or C. A represents those patients who underwent a CS after spontaneous onset of labour. B is representative of women who had a CS after induction of labour while $\mathrm{C}$ constitutes women who had a CS before onset of labour. Class 1 which represents nulliparous women with a term singleton pregnancy in normal presentation contributed $19.3 \%$ to the overall CS rate. $6.4 \%$ of all CS were done in multiparous women with a term singleton pregnancy and an unscarred uterus 
with the foetus normal presentation and were grouped to

class 3.

Table 1: Socio economic and obstetric characteristic.

\begin{tabular}{|c|c|c|c|}
\hline Sr. no. & Characteristic & Variables & Frequency (\%) \\
\hline 1. & \multicolumn{2}{|l|}{ Total number (n) } & 2831 \\
\hline 2. & \multicolumn{2}{|l|}{ Vaginal delivery (VD) } & $1274(45 \%)$ \\
\hline $2 \mathrm{a}$. & \multicolumn{2}{|l|}{ Spontaneous onset } & $88.4 \%$ of 1274 \\
\hline $2 b$. & \multicolumn{2}{|l|}{ Induced labour } & $11.6 \%$ of 127 \\
\hline 3. & \multicolumn{2}{|l|}{ Caesarean section (CS) } & $1557(55 \%)$ \\
\hline $3 a$. & \multicolumn{2}{|l|}{ Emergency CS } & $51.5 \%$ of 1157 \\
\hline $3 b$. & \multicolumn{2}{|l|}{ Elective CS } & $48.5 \%$ of 1157 \\
\hline 4. & \multicolumn{2}{|l|}{ Mean age (years) $($ Mean \pm SD) } & $27.32 \pm 2.65$ \\
\hline \multirow{2}{*}{5.} & \multirow{2}{*}{ Gravida } & Primi & $1097(38.71 \%)$ \\
\hline & & Multi & $1734(61.25 \%)$ \\
\hline \multirow{3}{*}{6.} & \multirow{3}{*}{ Socio economic status } & Kuppuswamy 1 and 2 & $758(26.77 \%)$ \\
\hline & & Kuppuswamy 3 & $975(34.44 \%)$ \\
\hline & & Kuppuswamy 4 and 5 & $1098(38.78 \%)$ \\
\hline \multirow{2}{*}{7.} & \multirow{2}{*}{ Body mass index (BMI) in $\mathrm{kg} / \mathrm{m}^{2}$} & Normal (18.5 - 24.9) & $2400(84.77 \%)$ \\
\hline & & Obese $(>25)$ & $431(15.22 \%)$ \\
\hline \multirow{2}{*}{8.} & \multirow{2}{*}{ Conception } & Spontaneous & $2460(86.89 \%)$ \\
\hline & & Assisted & $371(13.1 \%)$ \\
\hline \multirow{2}{*}{9.} & \multirow{2}{*}{ Booking visit } & Registered & $1697(59.94 \%)$ \\
\hline & & Referred & $1134(40.05 \%)$ \\
\hline \multirow{2}{*}{10.} & \multirow{2}{*}{ Education status } & More than $12^{\text {th }}$ class & $1066(37.65 \%)$ \\
\hline & & $12^{\text {th }}$ class or less & $1765(62.34 \%)$ \\
\hline
\end{tabular}

Table 2: Placement of women who underwent a CS in Robson's classes.

\begin{tabular}{|c|c|c|c|c|c|}
\hline $\begin{array}{l}\text { Robson } \\
\text { class }\end{array}$ & $\begin{array}{l}\text { Sub } \\
\text { class }\end{array}$ & $\begin{array}{l}\text { Total } \\
\text { patients in } \\
\text { the group }\end{array}$ & $\begin{array}{l}\text { Normal delivery rate } \\
\text { of the group } \mathbf{n}(\%)\end{array}$ & $\begin{array}{l}\text { Caesarean section rate } \\
\text { of the group } n(\%)\end{array}$ & $\begin{array}{l}\text { Contribution of the group to } \\
\text { total CS rate n (\%) }\end{array}$ \\
\hline 1 & - & $723(25.5 \%)$ & $422(58 \%)$ & $301(42 \%)$ & $19.3 \%$ \\
\hline \multirow{2}{*}{2} & $2 \mathrm{~A}$ & $162(5.72 \%)$ & $69(43 \%)$ & $93(57 \%)$ & $6 \%$ \\
\hline & $2 \mathrm{~B}$ & $27(0.95 \%)$ & $0(0 \%)$ & $27(100 \%)$ & $1.7 \%$ \\
\hline 3 & - & $730(25.7 \%)$ & $630(86 \%)$ & $100(14 \%)$ & $6.4 \%$ \\
\hline \multirow{2}{*}{4} & $4 \mathrm{~A}$ & $87(3.07 \%)$ & $71(81 \%)$ & $16(19 \%)$ & $1 \%$ \\
\hline & $4 \mathrm{~B}$ & $3(0.1 \%)$ & $0(0 \%)$ & $3(100 \%)$ & $0.2 \%$ \\
\hline \multirow{3}{*}{5} & $5 \mathrm{~A}$ & $99(3.49 \%)$ & $12(12 \%)$ & $87(88 \%)$ & $5.6 \%$ \\
\hline & $5 \mathrm{~B}$ & $0(0 \%)$ & $0(0 \%)$ & $0(0 \%)$ & $0 \%$ \\
\hline & $5 \mathrm{C}$ & $700(24.7 \%)$ & $0(0 \%)$ & $700(100 \%)$ & $45 \%$ \\
\hline \multirow{3}{*}{6} & $6 \mathrm{~A}$ & $24(0.84 \%)$ & $0(0 \%)$ & $24(100 \%)$ & $1.5 \%$ \\
\hline & $6 \mathrm{~B}$ & $0(0 \%)$ & $0(0 \%)$ & $0(0 \%)$ & $0 \%$ \\
\hline & $6 \mathrm{C}$ & $9(0.31 \%)$ & $0(0 \%)$ & $9(100 \%)$ & $0.6 \%$ \\
\hline \multirow{3}{*}{7} & $7 \mathrm{~A}$ & $20(0.7 \%)$ & $2(10 \%)$ & $18(90 \%)$ & $1.2 \%$ \\
\hline & $7 \mathrm{~B}$ & $0(0 \%)$ & $0(0 \%)$ & $0(0 \%)$ & $0 \%$ \\
\hline & $7 \mathrm{C}$ & $0(0 \%)$ & $0(0 \%)$ & $0(0 \%)$ & $0 \%$ \\
\hline \multirow{3}{*}{8} & $8 \mathrm{~A}$ & $18(0.63 \%)$ & $11(61 \%)$ & $7(39 \%)$ & $0.4 \%$ \\
\hline & $8 \mathrm{~B}$ & $0(0 \%)$ & $0(0 \%)$ & $0(0 \%)$ & $0 \%$ \\
\hline & $8 \mathrm{C}$ & $7(0.24 \%)$ & $0(0 \%)$ & $7(100 \%)$ & $0.4 \%$ \\
\hline \multirow{3}{*}{9.} & $9 \mathrm{~A}$ & $9(0.31 \%)$ & $0(0 \%)$ & $9(100 \%)$ & $0.6 \%$ \\
\hline & $9 \mathrm{~B}$ & $0(0 \%)$ & $0(0 \%)$ & $0(0 \%)$ & $0 \%$ \\
\hline & $9 \mathrm{C}$ & $0(0 \%)$ & $0(0 \%)$ & $0(0 \%)$ & $0 \%$ \\
\hline \multirow{3}{*}{10.} & $10 \mathrm{~A}$ & $194(6.85 \%)$ & $50(26 \%)$ & $144(74 \%)$ & $9.2 \%$ \\
\hline & $10 \mathrm{~B}$ & $11(0.38 \%)$ & $7(64 \%)$ & $4(36 \%)$ & $0.3 \%$ \\
\hline & $10 \mathrm{C}$ & $8(0.28 \%)$ & $0(0 \%)$ & $8(100 \%)$ & $0.5 \%$ \\
\hline
\end{tabular}


Table 3: Analysis of class 10 Robson.

\begin{tabular}{|l|llll|}
\hline Sub class & $\begin{array}{l}\text { Total contribution to the } \\
\text { CS rate }\end{array}$ & $\begin{array}{l}\text { Previous CS } \\
(\text { most common) }\end{array}$ & $\begin{array}{l}\text { Foetal distress } \\
\left(2^{\text {nd }} \text { most common) }\right.\end{array}$ & $\begin{array}{l}\text { Prolonged labour } \\
\left(3^{\text {rd }} \text { most common) }\right.\end{array}$ \\
\hline 10A & $144(92.3 \%)$ & $47(32.63 \%)$ & $35(24.3 \%)$ & $13(9.02 \%)$ \\
\hline $10 \mathrm{~B}$ & $4(2.5 \%)$ & 0 & $3(75 \%)$ & $1(25 \%)$ \\
\hline $10 \mathrm{C}$ & $8(5.12 \%)$ & $8(100 \%)$ & 0 & 0 \\
\hline
\end{tabular}

Similarly, nulliparous and multiparous women at term gestation with normal presentation who were given labour induction accounted to $6 \%$ and $1 \%$ respectively and $1.7 \%$ and $0.2 \%$ of these women were delivered by a CS respectively and these women are classified as group 2 and 4 respectively.

The highest CS rate was observed in class 5 which mainly comprises of women with a previous uterine scar, Almost, half of all CS (50.6\%) were one in this group. None of the mothers were given an induction and in this class $88.9 \%$ were operated before the onset of labour whereas $11.06 \%$ were operated after setting into labour.

A total of 53 breech presentations were delivered in primis and in multis over one year, of which 2 were delivered by vaginal route and the rest by CS. Hence groups 6 and 7 are responsible of an overall $3.3 \%$ of all CS. Similarly, women in group 9, who presented with an abnormal foetal lie were the smelled class with a contribution of $0.31 \%$ of overall presentations. All women in this group were delivered by a CS and this accounted for $0.6 \%$ of all the CS.

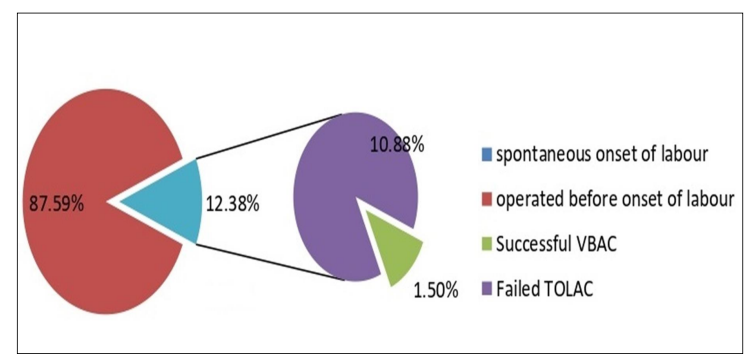

Figure 1: Mode of delivery in Robson class 5.

Deliveries of multifetal gestation pregnancies were categorised to group 8 and they contributed to $0.8 \%$ of all caesarean sections with $0.4 \%$ CS being performed after mother setting into labour and another $0.4 \%$ being performed before the mother set in labour. The third largest contributor to the overall CS was group 10, noted in women with a singleton cephalic preterm pregnancy which contributed to $10 \%$ of overall CS rate. Interestingly $3 / 4^{\text {th }}$ of mothers in this group had a CS compared to $1 / 4^{\text {th }}$ of them who had a VD.

The Robson group 5, 1 and 10 were the three largest contributors to the high institutional CS rates and were further dwelled into for a deeper understanding. Group 5 which consisted of women with a uterine scar comprised $28.2 \%$ of all women presenting for an institutional delivery. Out of these 799 women, 12.3\% (99 patients) presented in labour whereas the remaining presented and were operated before setting into labour. None of the women in this group were given an IOL as per institutional protocols. Of the 99 women who presented with spontaneous onset of labour, vaginal birth could be achieved in 12 women whereas the trial of scar was unsuccessful in the remaining 87 women. The same is shown in Figure 1.

The Robson Group 1 comprises of women at term gestation in their first pregnancy with normal presentation and who underwent a CS before setting into labour, the three most common reasons for doing a CS in this group were, foetal distress (44\%), cephalopelvic disproportion (24\%) and prolonged labour (20\%).

Class 10 of Robson classification includes mothers with singleton pregnancies who had a CS before completion of the $37^{\text {th }}$ week of gestation. This was the $3^{\text {rd }}$ largest contributor to the institutional CS rate and was further analysed to recognize the indications for $\mathrm{CS}$ in this group. $10 \mathrm{~A}$ was the largest subgroup whereas $10 \mathrm{~B}$ and $10 \mathrm{C}$ contributed less than a $10^{\text {th }}$ to the class. The same is depicted in Table 3.

\section{DISCUSSION}

The clinical audit noted a CS rate of 55\% with almost half of them being done for elective reasons. It was found out that the most common patient group to undergo a CS in the institute were those with previous uterine scars followed by a $19.3 \%$ contributed by term primi mothers with cephalic presentation complicated with foetal distress or cephalopelvic disproportion. CS done for breech presentation and multifoetal gestation contributed only $3.3 \%$ and $0.8 \%$ respectively, to the overall rate. Group 9 of Robsons which includes women with abnormal lie was the smallest contributor $(0.6 \%)$.

The audit explicitly shows that the institutional CS rates are high in comparison to the rates observed in similar institutes and non-teaching hospitals. A study done at the ESIC Medical College Hospital in West Bengal showed a CS rate of $39 \%$ in $2015 .^{10}$ Similarly an audit at a tertiary care teaching hospital in 2017 revealed a CS occurrence of $36.88 \%{ }^{2}$ Another medical college hospital in central India audited the CS for 4 year and found a $48.1 \%$ prevalence of abdominal deliveries. ${ }^{3}$ These wide 
variations could be attributed to the varied population samples that present to these centres for their delivery. This is one reason why, not much inference can be deduced when CS rate is analyzed in isolation.

The Robson system appears to be well validated and is used extensively in CS audits at local and national levels. The WHO recommends and describes Robson as a gold standard for any the analyses of CS rates. ${ }^{9}$ More so, it has gained sufficient popularity that it can bring in uniformity in assessment and would make the results comparable, internationally. This is evident from its recent widespread use in systematic reviews and clinical audits. ${ }^{1,11}$ Boatin et al in their systematic review concluded that Robson provides a stable framework, both alone and in conjunction with other approaches for categorizing and analyzing data in audit cycles. ${ }^{1}$ Several authors have sub classified Robson so that the circumstances that lead to a CS in a particular class can be well elucidated. ${ }^{12,13}$ This audit also used the modified Robson criteria as it maintains the essence of Robson apart from demonstrating additional information for most of the classes of Robson.

The task force of the Indian Council of Medical Research (ICMR) recognizes that there is a delicate balance of benefits and harms as far as a planned vaginal delivery is concerned in women with previous CS. ${ }^{14}$ The task force in its multicentric audit at 30 medical colleges in India concluded that the choice of repeat CS or planned VD in a mother with a scarred uterus is one of the most significant and challenging issues in obstetric practice. ${ }^{14}$ This is because of the risk of uterine rupture that comes inherently associated with a trial of labour after caesarean (TOLAC) which is an obstetrician's nightmare. This impression was very strongly reflected in this audit wherein $45 \%$ of all CS were done in mothers with a previous scar before they set into labour in addition to $5.6 \%$ done in those who spontaneously set into labour. Astonishingly not even a single case of previous CS was taken up for induction of labour.

Similarly, an audit performed by Thool et al in India revealed that previous $\mathrm{CS}$ was the largest contributor of Category $3 \mathrm{CS}$, which includes women with no maternal or foetal compromise but requires an urgent delivery. ${ }^{2}$ Another audit at a medical college in Bhopal found that the second most common indication document in operative notes was previous $\mathrm{CS}^{3}$ Keeping with such trends a Cochrane review in 2011 concluded that a second opinion should always be sought when planning the mode of delivery in those with previous CS apart from a pre CS consultation and a post CS surveillance. ${ }^{15}$

CS done in Primis at TG despite having a normal presentation need to be closely anlyzed because operative intervention in them leads to a scar that mars their chances of normalized birth in future. This constitutes the first class of Robson and was found to be the second largest CS contributor. A deeper analysis revealed foetal distress to be the most common indication in this group. The decision for CS in this class appears to be more stable and unaffected by interventions as was elucidated by Charles et al. The study found only a $0.38 \%$ reduction in CS rates in class 1 Robson after implementing clinical protocols to reduce CS rates. The contribution to the overall CS rate in this multicentric trial after intervention was found to be $25.07 \%{ }^{16}$

The contribution of Breech presentation and abnormal lies to CS was found to be negligible in our audit. Similar results have been described by Tanaka et al who reported a $0.8 \%$ and $1 \%$ contributory rate of nulliparous and multiparous breech respectively, apart from another $0.8 \%$ attributed to abnormal lie. ${ }^{12}$ Contrary findings can be seen in an audit at Thissur Medical College where breech presentations in nulliparous and multiparous women was responsible for a $13.1 \%$ of institutional CS rate. ${ }^{13}$ An audit done at People's Medical College noted an 8.2\% of all CS were done due to malpresentations and malposition's. A consistent finding over several studies is that there were no inductions done for breech presentation and abnormal lie. ${ }^{12,13}$ The DECIDE, a cluster multicentric randomized controlled trial noted an increase in the rates of $\mathrm{CS}$ for breech presentation by $2 \%$ after introducing written institutional delivery policy. ${ }^{16}$

A study in Ethiopia in 2017 revealed $2.5 \%$ of all indications for CS were multifoetal gestation. ${ }^{17}$ An Australian audit in 2017 observed that $0.8 \%$ of all section were done for multiple pregnancies. ${ }^{12}$ The sister medical college in West Bengal reported that $4.9 \%$ of all CS were done for multifoetal pregnancy. ${ }^{10}$ This study audit noted a $0.8 \%$ CS rate is Robson group 8 . These differences could be explained by the varying rates of CS in different parts of the world and our country beside differences in populations due to the mode of conception and based on the level of care and referral. An interesting point established by Charles et al, is that huge differences can be bought by reducing the number of $\mathrm{CS}$ is mothers classified to Robson 8 by introducing clinical algorithms with an absolute risk reduction by 1.6 times. ${ }^{16}$

The class 10 of Robson indicates all women who underwent a CS before term gestation. Almost a 10th of all institutional CS were in this class of women. The CS in this class was again repeat CS done to avoid dehiscence or rupture. Foetal distress was also noted to contribute heavily in these women leading to a CS. This can be explained by the fact that delivery in preterm babies is planned usually due to some maternal and/ or foetal morbidity and that a majority of these conditions place the foetus at risk of hypoxia which can culminate into distress. Almost $90 \%$ of all patients in Group 10 had a CS after the onset of labour which implies that they had to be delivered by a CS either due to an intrapartum complication or to allay the possibility of scar complications.

As the CS rates increase globally, there is a growing concern for the need to analyse it and an expectation that it be reduced if it is medically unindicated or unethical. A 
four-year survey by the mediterrane an network which evaluated around 250,000 birthing mothers with 55,000 CS safely concluded that performing audits can have considerable reduction in CS rate apart from which the audit also emphasized the need to edify specialty trainees in audit cycles to improve CS rates. ${ }^{18}$ Large scale audits conducted at national level maybe recourse consuming and in the absence of a political will it can prove to be arduous task to take up such projects, a plausible solution to this can be the peer review audits proposed by Zheng et al which are simple and less expensive but can prove to be an inexpensive tool for clinical governance. ${ }^{19}$

Irrespective of the method used for audit, the most imperative entity is the spirit of enquiry and knowledge acquisition which can then be translated for patient beneficence. Though it is crucial that a CS should never be denied to a mother who rightfully deserves one for her and her foetal betterment, it is also indispensable that all CS being done for non-indicated purposes be tackled at all levels to uphold the value of non-maleficence, the foremost tenet of modern medicine.

\section{CONCLUSION}

The audit conducted revealed several essential trends in $\mathrm{CS}$ at the institute. Though it would be unfair to say that all of our CS were medically indicated, it would also be an inappropriate over-exaggeration to say that most of the CS were ethically questionable. The results of this audit lead to an invitation of the administrative and clinical decision makers on the same board that lead to the placement of several interventions that would, in near future to subjected to rigorous evaluation of performance to ensure that they do the good they intend to do but not at the cost of a single mother being denied a CS when she requires it.

Funding: The study was funded internally as a part of quality improvement project approved by the administration of the ESIC Medical College, Hyderabad Conflict of interest: None declared

Ethical approval: The study was approved by the Institutional Ethics Committee ESIC Medical College

\section{REFERENCES}

1. Boatin AA, Cullinane F, Torloni MR, Betran AP. Audit and feedback using the Robson classification to reduce caesarean section rates: a systematic review. BJOG. 2018;125:36-42.

2. Thool KN, Jain SM, Shivkumar PV, Jain MA, Podder MR. A clinical audit and confidential enquiry of caesarean section indications at rural tertiary health care centre. Int J Reprod Contracept Obstet Gynecol. 2017;6(4):1478-83.

3. Bharadwaj M, Modi JN. A four year audit of deliveries by caeserean section at a medical college hospital in Central India. Inter J Reprod Contracept Obstet Gynecol. 2015;4(6):1776.
4. Runmei a M, Lao Terence TB, Yonghu S, Hong X, Yuqin T. Practice audits to reduce caesareans in a tertiary referral hospital in south-western China. Bulletin World Health Organization. 2012;90:48894.

5. WHO statement on Caesarean Section rates, 2015. Department of Reproductive Health and Research. World Health Organization, Geneva. Available at: https://apps.who.int/iris/bitstream/handle/10665/161 442/WHO_RHR_15.02_eng.pdf;jsessionid=FE8706 7798CEDEAF0A1CE06120A6A40A? sequence $=1$. Accessed $22^{\text {nd }}$ December 2019.

6. RCOG statement on The Lancet series about caesarean births. 2018. Available at: https://www.rcog.org.uk/en/news/rcog-statementresponding-to-the-lancet-story-on-caesarean-sectionrates/. Accessed $19^{\text {th }}$ December 2019.

7. Radhakrishnan T, Vasanthakumari KP, Babu PK. Increasing trend of caesarean rates in India: Evidence from NFHS-4. JMSCR. 2017;5(8):26167-76.

8. Walshe KM. Principles for Best Practice in Clinical Audit: National Institute for Clinical Excellence. Abingdon, Oxon: Radcliffe Medical Press, 2002.£ 29.95 (£ 19.95 for NHS staff). 208 pp. ISBN 185775 976 1. Qual Saf Health Care. 2002;11(4):392.

9. Robson Classification. Implementation Manual. World Health Organisation. 2017. Available at: https://www.who.int/reproductivehealth/publications /maternal_perinatal_health/robson-classification/en/. Accessed $19^{\text {th }}$ December 2019.

10. Sarkar D, Bhadra B, Saha MM, Sarkar S. Caesarean section rates in a rural tertiary care hospital in West Bengal. Med Pulse- Inter Med J. 2016;3(9):862-5.

11. Kempe $P$, Vikström-Bolin M. The continuous audit of events and outcomes of labour and birth using the Ten Group Classification System and its role in quality improvement. Eur J Obstet Gynecol Reprod Biol. 2019;237:181-8.

12. Tanaka K, Mahomed $\mathrm{K}$. The ten-group robson classification: a single centre approach identifying strategies to optimise caesarean section rates. Hindawi Pub Corpo Obstet Gynecol Inter. 2017:5.

13. Jacob KJ, Jayaprakash M, Hibina K. TMC (Thrissur Medical College) modified Robson criteria for caesarean sections. Int $\mathbf{J}$ Reprod Contracept Obstet Gynecol. 2017;6(11):5038-43.

14. Dhillon BS, Chandhiok N, Bharti S, Bhatia P, Coyaji KJ. Vaginal birth after cesarean section (VBAC) versus emergency repeat cesarean section at teaching hospitals in India: an ICMR task force study. Int J Reprod Contracept Obstet Gynecol. 2014;3(3):592-7.

15. Khunpradit S, Tavender E, Lumbiganon $P$, Laopaiboon M, Wasiak J, Gruen RL. Non-clinical interventions for reducing unnecessary caesarean section (review). In: The Cochrane Library. Chichester: Wiley; 2011:6.

16. Kaboré C, Ridde V, Chaillet N, Bocoum FY, Betrán AP. DECIDE: a cluster-randomized controlled trial to reduce unnecessary caesarean deliveries in Burkina Faso. BMC Med. 2019;17:87.e1-e14. 
17. Gebre S, Negasi A, Hailu A. Criteria Based clinical audit of cesarean section in a general hospital in West Tigray, Ethiopia. J Women's Health Care. 2017;6(410):2167-420.

18. Lesieur E, Blanc J, Loundou A, Claquin A, Marcot $\mathrm{M}$, Heckenroth $\mathrm{H}$, Bretelle $\mathrm{F}$. Teaching and performing audits on caesarean delivery reduce the caesarean delivery rate. PLoS One. 2018;13(8):e0202475.

19. Ng ZY, Tan JK, Tan EL, Kanagalingam D, Tan LK. Peer review audit of caesarean sections in a tertiary hospital. Clin Surg. 2017;2:1628.
Cite this article as: Yerra AK, Khan MI. Analysing trends in caesarean sections at a tertiary care teaching hospital in South India: findings from a clinical audit using Robson criteria. Int J Reprod Contracept Obstet Gynecol 2020;9:1463-9. 